\title{
A Case Study of Toyota's Globalization Strategy while Entering Chinese Market
}

\author{
Gao Guowei \\ State Grid Energy Research Institute, Beijing 100052, China
}

\begin{abstract}
Chinese market is very important for multinational auto manufacturers, and a multinational's practice of entering Chinese market is a good case for globalization strategy. In this paper we review Toyota's strategy of entering Chinese auto market, to evaluate the cooperation form, geographical distribution, and customization production. Toyota's strategy in Chinese auto market is relatively successful and a more aggressive goal is being implemented.
\end{abstract}

Keywords: globalization; multinational; strategy

\section{CHINA AUTOMOBILE MARKET}

In the late 1980s, because of the open economy policy, the demand of automobiles increased. However, by then China didn't have sufficient technology to enhance the production and quality. In order to compensate the gap between the limited technology and the increasing demand, Chinese government has put a lot of efforts in raising high technology. On the other hand, the automotive industry was not mature yet and Chinese government, in order to meet the domestic demand, began to encourage establishing the JVs, which was an important approach to modernize the automotive industry. In terms of the future market po- tential, foreign carmakers invested hugely in the China market.

In terms of the JVs, Chinese government knew clearly if the Chinese side partners cannot learn the core technology from their foreign side partners, the JVs would not be truly helpful to upgrade and boost the Chinese auto industry. However, the potential market gave Chinese government a strong leverage set up the regulation and rules which are a bit favorable to Chinese side partners in the forms of JVs with foreign investors.

In 1994, the Chinese government decreed a related Auto Policy to emphasize that the automotive industry will be one of the major pillar industries in the future. At the same time, a series of regulations and rules related to the FDI were lunched to improve and protect the domestic auto industry. Because having less competitiveness, the domestic manufacturers were accordingly under the protection made by the Chinese government. The protection included the limited imported quotas and higher tariff around $80 \%$ to $100 \%$ on both the CBU vehicles and parts and components. Besides, another important protection is to require $40 \%$ LCR.

In 2001, China successfully attended the World Trade Organization (WTO) whose principle is to ensure that global trade can move freely and fairly. One of the very important measurements is to reduce the barriers for international trade. 
Based on the agreement, China is needed to modify its regulations and rules to comply with the principle and, on the other hand, WTO provided a certain period functioning as the buffer to give Chinese manufacturers sufficient time which was 5-year period for protection, to alter its management to meet the WTO requirements. Within this 5-yearperiod, Chinese government should reduce the import tariffs of cars to $25 \%$ as well as the parts to $10 \%$ gradually. After the 5year protection, the quota on the imported cars should be cancelled out.

In 2004, in order to totally comply with the WTO agreements and enhance the current industry structure, new Auto Policy was published. The 2004 Auto Policy unwound many constraints on the basis of 1994 Auto Policy, to favor the foreign investors who accordingly could enjoy more benefit from the WTO agreements. Besides, because of the issue of environment protection, the 2004 Auto Policy also encourages the development of the ecological compact cars.

In Chinese auto market, JV is the only way to enter this industry by foreign car makers. Generally speaking, in this form of cooperation, the foreign side partners provide higher advanced technologies and the Chinese side partners is responsible for providing the local strategy and knowledge and public relation.

However, in order to gain more advantages in the JV formed cooperation, foreign side partners would implement some ways to keep its controlling stance. This most common way is to leverage by its advanced technology. Usually, those foreign side partners only provide basic technology to the JV but keep the latest ones. Moreover, because the reduction of imposition of the quota and tariff, direct import become another alternative. Lastly, foreign carmakers may choose to es- tablish various functional entities which assume the job of materials storage and distribution of logistics in order to achieve multiple purposes such as shortening the suppliers' delivery time, improving the supply chain, or building a more effective system.

After entering WTO in 2002, Chinese auto parts industry was highly transformed. In 2006, the total value of auto parts sector reached 67 billion in 2006 . This figure is 2.5 times growth in just 4 years. The main factor for the booming was the fast growing demand from the automobile manufacturers in China. The policy that assisted the growth of auto manufacturing was very effective, both domestic and foreign manufacturers invested huge money and energy in hope of the future benefit.

Furthermore, the increasing automotive demand also benefited the parts suppliers which made use of the huge advantage in China's labor lower cost, favorable policies and the large market demand. However, there are still some problems in Chinese auto parts market. First of all, the auto parts sector in China is small-sized and fragmented geographically. Second, the quality of the local produced parts as compared to the foreign counterparts is relatively worse and only very limited number suppliers are able to earn the contract with the major foreign carmakers.

However, with the Chinese auto demand increasing, more and more foreign car makers introduced their own suppliers outside China to directly invest in Chinese market. Moreover, because the JVs in China need to meet the required $40 \%$ LCR, more and more foreign carmakers will expand their technology and investment and the parts suppliers in China can expect a more optimistic market growth in the future. 


\section{TOYOTA IN CHINA MARKET}

In the Chinese auto market, Crown was the earliest export Japanese cars. At the early stage, Toyota had the intention to cooperate with local car producer; however, the unstable politics prevented from a further development. In the 1980s, the Chinese market roused the first wave of JV; Chinese government also pushed the progress by issuing a series of industry policies in hope of exchanging for advanced vehicle production technology. However, by then Toyota wanted to preserve its technology and the market was yet mature in China; Toyota suspended the JV plan. Instead, Toyota provided part of the skill to help the local vehicle producer, Tianjin Automotive Industry (TAIC, Now is Tianjin FAW Xiali Automobile) to produce Xiali by Toyota's subsidiary, Daihatsu Motor.

\subsection{Form of JVS}

In June 1993, Toyota in Beijing established its Toyota Motor (China) Ltd. After that Toyota constructed its own parts production line and many suppliers followed to establish the parts factories to assist Toyota's production. In 1996, Toyota declared the JV of Tianjin FAW Toyota Engine (TFTE) with Tianjin Auto Group. This company was to produce the engines which Toyota needed in production.

In 1998, Toyota and First Automobile Works (FAW) formed Sichuan FAW Toyota Motor (SFTM) to produce the local vehicles and SFTM is the first local production line in China. In June, 2000, Toyota and Tianjin Auto Group formed another JV called Tianjin Toyota Motor, which began to produce Vios in 2002. By then, Toyota's launch of production in China was 15 years slower as compared with VW and 5 years as compared to GM.
Because FAW acquired Tianjin Auto Group in 2002, Toyota and FAW signed another agreement in May 2002; thus Tianjin FAW Toyota Motor was renamed for Tianjin FAW Toyota Motor (TFTM). Under current situation, China has a law which allows any MNC to form JV with at most two Chinese Corporations. In order to preserve the flexibility to cooperate with other Chinese Corporation, Toyota asked FAW to acquire SFTM. This adjustment gave the room for Toyota to form another JV with Guangzhou Automobile Industry Group (GAIG) in 2004.

\subsection{Geographic Strategy}

Initially Toyota expanded the market from northern cities such as Tianjin and Changchun; however, Toyota didn't ignore the importance of the South China. In 2004, Guangzhou Toyota Motor Company (GTMC) was established by Toyota and GAIG. GTMC was another base to expand the South China market. In 2004, Toyota and GAIG formed another parts manufacturing corporation called Guangzhou Toyota Engine (GTE), which can produce 300 thousand engines and export to Japan.

In 2006, GTMC began producing Camry with a capacity of 100 thousand units. By then Toyota planned to occupy $10 \%$ share of the China auto market, which means over1 million vehicles sales, and obviously Toyota's strategy was geographically to cover the coastline cities to expose more lucrative market between North and South China.

In addition, the $\mathrm{JVs}$ in the south and the north respectively manufacture different products. In 2005, TFTM released Crown in China market; in the following year, in 2006, GTMC published Camry. Although they are the same type of products, both products target different levels 
of customers. This is the first time Toyota implement this strategy. In late 2006, Vios was introduced by TFTM; however, because of focusing on the sale of Camry, GTMC published the similar product, Yaris, until 2008.

In 2009, TFTM and GTMC, almost the same time, introduced their products, RAV4 and Highlander. Basically Toyota assigned different product to both sides. On one hand it is to reduce the phenomenon of cannibalization; on the other hand, this strategic, to some extent, complement the two companies mutually. Explicitly the products of the two companies can transmit the image that Toyota has a well rounded productions portfolio; implicitly, this strategy can avoid any severe competition and have the two JVs become good strategic units in facilitating Toyota's market strategies in China.

\subsection{Customization Production}

In the perspective of production, Toyota brought the JIT concept into the production process, so the strict requirements of suppliers in terms of cost, quality, and delivery are very critical. As followed the establishment of JVs of Toyota, Toyota's suppliers swamped to China to setup research or manufacturing plant as well. Toyota's major parts suppliers include DANSO, AISIN, Toyota Boshoku, JTEKT, etc.

As the China auto market is becoming mature, customers' needs become diversified as well; accordingly Toyota has been adopted the customization sale in China market. The feature of the customization is that it can satisfy the customers' preferences in terms of color or even brand of parts. In the current China market, according to the survey, the middle class becomes the major force of the vehicles consumption. One of the characteristics of this level is that they focus on the auto's brand, functions and personalization and customization can serve the kind of function and this implementation gradually influences the other auto manufacturers, including the domestic producer, Chery.

Although relatively Toyota came to China markets lower than other major producers, it has unparalleled and competitive advantage, which is the rich globalized experience and the particular TPS, to catch up with them. With Toyota's parts suppliers entering directly to China and the integration of the knowledge-based and geographicallybased strategies, Toyota has large confidence in the future development of China market. Therefore, Toyota' sin-house estimation reveals a very ambitious target that as of early 2010 Toyota will have vehicles sale above one million units.

\section{CONCLUSION}

Internationalization strategy of Toyota has changed during the first half of the 1980s from export-orientation to the localization-orientation, excepting for early SKD assembly in some countries and small localized production in Brazil. The enormous change was incurred by local governments' protectionist policy, which is the biggest driver to force Toyota change its strategy despite of its preference to export due to the sake of TPS, which presumably is not transferable. The trade conflicts from the 1970s made by the voluntary restraint of export between the U.S. and the Japanese government triggered Toyota to realize its foreign production, and this trend was significantly reinforced by its "New Global Business Plan” from 1994.

Due to the TPS effect, Toyota needs to train their suppliers in order to get advances towards achieving the best goal. It can be seen that Toyota paid more atten- 
tion on the suppliers' training and that those suppliers enjoy the advantages for being provided improved product design, technology innovation, and services. In addition, Toyota reinforced its ties with group companies by setting up its holding company which was mainly used to monitor its group companies. Moreover, Toyota has controlled the quality of the automotive components by mainly investing their own suppliers, such as Daihatsu and Hino.

Based on the trend of environment protection, new technology needs to achieve further breakthrough. In order to maintain the advantage of technology and to get closer to local demand, Toyota formed strategic alliances. The best example was that Toyota cooperated with Matsushita or with PSA Peugeot Citroen and invested in the ecological vehicles research, as it was shown by the launch of the Prius and Aygo.

On the other hand, in order to strengthen the self-reliance of those foreign production bases, Toyota launched the IMV project. Toyota captured the respectively geographical advantages of those markets and further cut the cost. Besides, the establishment of GPC mitigated the problem of communication and laid the foundation for Toyota's IMV project.

The rise of China is an important event in the world for this century. Recently the auto market in China has been highly changing due to the entry of WTO which also affected the environment of the auto market as well. As followed by China's entry into WTO, it domestic regulations and LCR changed accordingly. The tempting market attracted all the major multinational carmakers all over the world, making China's market a new and significant battlefield of their world wide competitions. All the auto giants are taking off from the same scratch line; therefore the recent corresponding behaviors of those auto giants, especially their strategies in China, are worth studying and would create new empirical knowledge. The possible generalization of the firms we study could be helpful not only for the whole automobile industry, but also for all the MNCs of other industries in China.

Toyota's strategy, after formed the JVs with FAW and GAIG, is obviously serving China market from north and south to cover the coastline market which is relatively lucrative. Furthermore, the suppliers following Toyota to invest in local China market can largely support Toyota to implement its TPS in China. As the China's auto market is getting mature, Toyota's ambition is to reach 10 million vehicles in China market in 2015.

\section{REFERENCES}

[1] United Nations Industrial Development Organization, The Global Automotive Industry Value Chain: What Prospects for Upgrading by Developing Countries, Sectoral Studies Series, 2003

[2] Tetsuji Kawamura, Potential of Asian Economic Integration: A Perspective from the Strategy of Japanese Enterprises. (New Delhi, India: Research and Information System for Developing Countries, 2008)

[3] Christopher M. Law, Restructuring the Global Automobile Industry. (New York, NY: Routledge, Chapman and Hall, Inc., 1991)

[4] Bernd Gottschalk, and Ralf Kalmbach, Mastering automotive challenges. (Philadelphia PA: Kogan Page Limited, 2007) 